\title{
Preservation of myocardial function by mechanical circulatory support during prolonged ischaemia
}

\author{
L. Tuon-A-Meeuw, O. M. Hess, L. V. Segesser, G. Suetsch, B. Leskosek and M. Turina \\ Department of Internal Medicine, Cardiology and Department of Cardiovascular Surgery, University Hospital Zürich
}

KEY WORDS: Mechanical circulatory support, myocardial ischaemia, left ventricular function, reperfusion, ultrasonic crystals.

The effect of mechanical circulatory support on left ventricular ( $L V)$ function was evaluated during prolonged myocardial ischaemia. Regional wall thickening of a normal and an ischaemic $L V$ region were determined in eight calves (mean body weight $76 \mathrm{~kg}$ ) using pairs of ultrasonic crystals. LV end-diastolic ( $\mathrm{mmHg}$ ) and peak systolic ( $\mathrm{mmHg}$ ) pressure as well as maximum dP/dt ( $\left.\mathrm{mmHg} \mathrm{s}^{-1}\right)$ were calculated from $L V$ high-fidelity pressure tracings. The left circumflex coronary artery was ligated proximally for $6 \mathrm{~h}$ and reperfused for $18 \mathrm{~h}$. Circulatory support by the assist device was performed from the beginning of ischaemia to the end of the experiment. After a mean time of $4 \mathrm{~h}$ all animals showed ventricular fibrillation, which was converted successfully in six animals after a mean time interval of $5 \mathrm{~h}$. Five animals survived after $24 \mathrm{~h}$. The non-surviving animals had larger infarcts, greater creatine kinase release and a larger drop in cardiac output during ischaemia. Haemodynamic measurements were carried out after turning off the assist device. Inotropic stimulation with $0.68 \mathrm{mg} . \mathrm{min}^{-1}$ dopamine i.v. was performed at the end of the study. LV regional function showed systolic bulging during myocardial ischaemia. After $18 \mathrm{~h}$ of reperfusion, the ischaemic wall recovered and showed normal systolic wall thickening in the presence of an increased $L V$ preload. $L V$ relaxation was prolonged after reperfusion, suggesting diastolic dysfunction.

It is concluded that mechanical circulatory support is effective in protecting myocardial function during prolonged ischaemia in approximately two-thirds of the animals, despite severe ischaemic ventricular dysfunction and intermittent ventricular fibrillation.

\section{Introduction}

Severe myocardial ischaemia is associated with acute left ventricular (LV) failure and irreversible myocardial damage. Unloading of the ventricle can be used to avoid acute heart failure and to limit myocardial damage ${ }^{[1-5]}$. Extracorporeal circulatory support has been used successfully in patients with severe heart failure as temporary treatment for cardiogenic shock and as a bridge to transplantation ${ }^{[6-9]}$.

The purpose of the present study was to evaluate whether myocardial function can be preserved during prolonged myocardial ischaemia by immediate and complete unloading of the heart using an paracorporeal ventricular assist device.

\section{Material and methods}

Eight calves with a mean body weight of $76 \mathrm{~kg}$ underwent left thoracotomy under general anaesthesia with $0.25 \mathrm{mg} \mathrm{.} \mathrm{kg}^{-1}$ polamivet (morphine derivative) and $0.04 \mathrm{mg} . \mathrm{kg}^{-1}$ combelen (phenothiazine derivative) in combination with $10 \mathrm{mg} \cdot \mathrm{kg}^{-1}$ pentothal (barbiturate). Animal care was in accordance with the principles of 'laboratory animal care' at our hospital.

The left atrium and the descending aorta as well as the right atrium and the pulmonary artery were cannulated

Accepted for publication on 23 April 1992.

Correspondence. Otto M. Hess, Cardiology, Medical Polıclinic, University Hospital, Raemistrasse 100, 8091 Zürich, Switzerland. and connected to a ventricular assist device (see below). An $8 \mathrm{~F}$ Millar pigtail micromanometer catheter was inserted through the left atrial appendage into the left ventricle to measure $\mathrm{LV}$ pressure. An $8 \mathrm{~F}$ pigtail catheter was positioned in the ascending aorta to measure aortic pressure. Pairs of ultrasonic crystals were implanted in the region perfused by the left anterior descending coronary artery (=control region) and in the region perfused by the left circumflex coronary artery (= ischaemic region) to measure LV wall thickness ${ }^{[1,12]}$. Myocardial ischaemia was induced by proximal ligation of the left circumflex artery (Fig. 1). The experiments were carried out with the chest open and were haemodynamically monitored for the whole period. Blood gasses, $\mathrm{pH}$, potassium and haematocrit were controlled routinely during the experiment and corrected if necessary.

\section{VENTRICULAR ASSIST DEVICE}

A ventricular assist device (model BVS 5000 Abiomed Inc., Danvers, MA, U.S.A.) was used to support the left and right ventricles ${ }^{[9,10.13]}$. This device includes a driving unit and a disposable paracorporeal blood system (Fig. 2) which are connected to the right atrium and the pulmonary artery or the left atrium and the aorta, respectively. The assist device contains two chambers and two trileaflet valves for flow direction. The inflow in the atrium is continuous and passively controlled by gravity. Ventricle outflow is pulsatile and pneumatically activated. The bladder and valves are polyurethane. Adequate filling of 


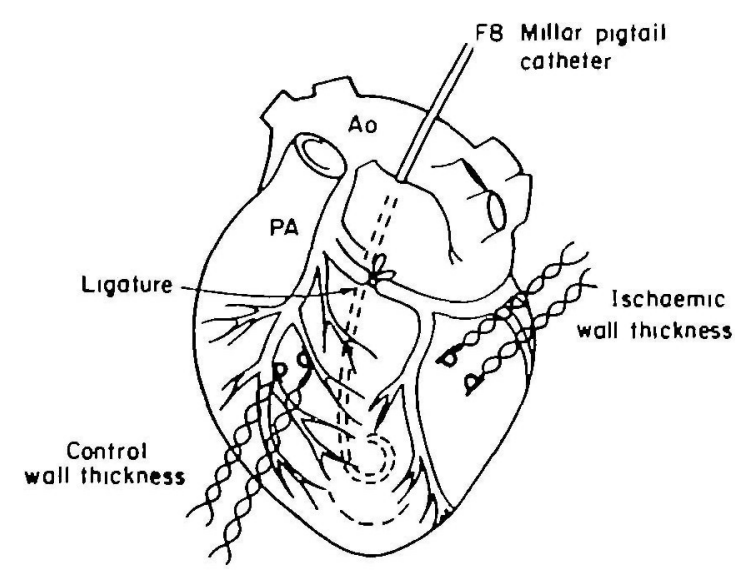

Figure 1 Schematic drawing of the instrumentation used in the present animal preparation. A F 8 Millar micromanometer catheter was introduced through the left atrial appendage into the left ventricle. Pairs of ultrasonic crystals were implanted to measure left ventricular wall thickness in a control ( $=$ left anterior descending coronary artery) and an ischaemic (=left circumflex coronary artery) region. The left circumflex coronary artery was ligated proximally to induce myocardial ischaemia. Ao: aorta; PA; pulmonary artery.

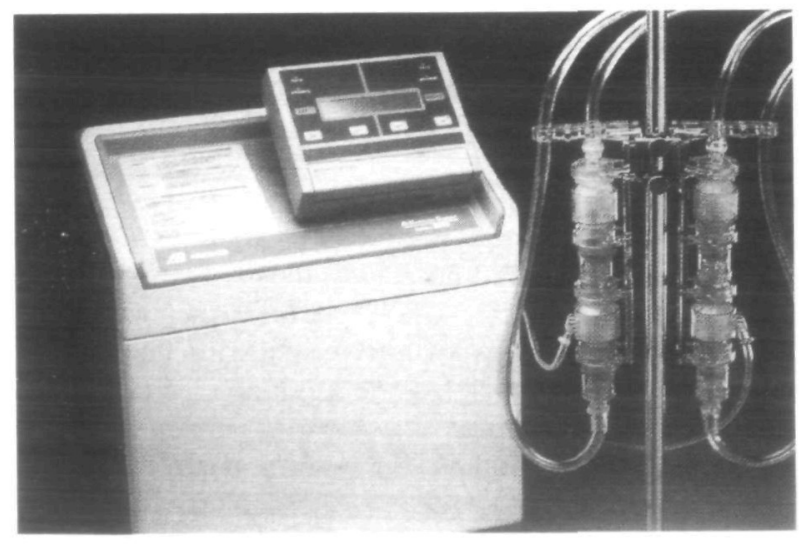

Figure 2 The Abiomed biventricular assist device (BVS 5000) with the driving unit, two artificial ventricles and the paracorporal blood pump system. The artificial atrium is filled passively by gravity, whereas the artificial ventricle is activated pneumatically. The blood flow is pulsatile.

the artificial atrium is assured by placing it approximately $20 \mathrm{~cm}$ below the left or right atrium (Fig. 2). The performance characteristics of the ventricular assist device have been published previously $y^{[9.10,13]}$.

\section{EXPERIMENTAL PROTOCOL (FIG. 3)}

After completion of the instrumentation, there was an interval of 10 to $15 \mathrm{~min}$ so that the haemodynamic variables could stabilize. The control run was then performed, after which the circumflex artery was ligated for a total duration of $6 \mathrm{~h}$. Haemodynamic measurements were repeated after $2 \mathrm{~min}$ as well as after $6 \mathrm{~h}$ of ischaemia. During the short period in which the measurements were

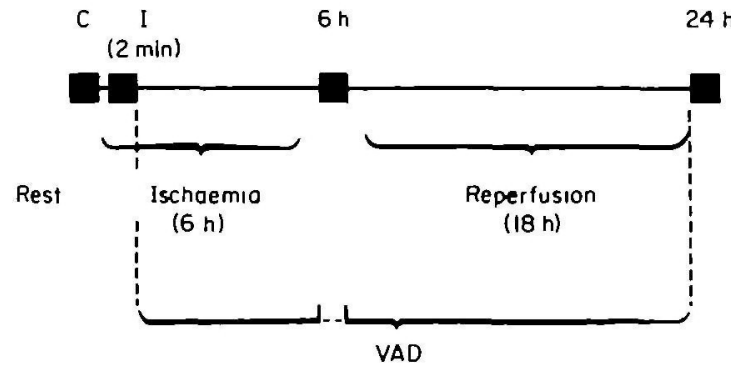

Figure 3 Experimental protocol: haemodynamic measurements were performed at rest (C), after $2 \mathrm{~min}$ (I) and $6 \mathrm{~h} \mathrm{(6h)} \mathrm{of} \mathrm{ischaemia}$ as well as after $18 \mathrm{~h}$ of reperfusion $(24 \mathrm{~h})$. Ventricular unloading was started immediately after the induction of ischaemia and ended $24 \mathrm{~h}$ after the beginning of the expenment. VAD: ventricular assist device.

performed, the assist device was stopped. Six hours after ligation of the circumflex coronary artery, the vessel was released and the heart reperfused for $18 \mathrm{~h}$. Unloading of both ventricles was performed from the beginning of ischaemia to the end of the experiment, except when haemodynamic measurements were carried out (Fig. 3). At the end of the experiment, the assist device was turned off and the haemodynamic measurements were repeated under inotropic stimulation with dopamine. The average dose given was $0.68 \mathrm{mg}$ dopamine per min.

\section{Data analysis}

LV pressure tracings were digitized manually for an entire cardiac cycle using an electronic digitizer (Numonics Corp.) interfaced to a computer PDP 11/34. Data were printed out on a Versatec printer-plotter (130 data points per beat). The time constant of isovolumic relaxation and the extrapolated baseline pressure (pressure at $\mathrm{dP} / \mathrm{dt}=0$ ) were calculated as the negative reciprocal of the slope of the linear regression between pressure and negative $\mathrm{dP} / \mathrm{dt}$ during isovolumic relaxation ${ }^{[14]}$. The isovolumic relaxation period was defined as the time interval beginning immediately after maximal negative $\mathrm{dP} / \mathrm{dt}$ and ending when pressure had decreased to $5 \mathrm{mmHg}$ above LV end-diastolic pressure ${ }^{[14]}$. LV end-diastolic pressure was defined as the pressure at $40 \mathrm{~ms}$ before the peak $R$ wave in the ECG. LV end-systolic pressure was defined as the pressure at the aortic incisura ${ }^{[15]}$. LV wall thickness tracings (Fig. 4) were digitized manually. End-diastolic wall thickness was defined as the wall thickness at the time of end-diastolic pressure and end-systolic wall thickness at the time of end-systolic pressure. Systolic wall thickening was calculated as end-systolic minus end-diastolic wall thickness divided by end-systolic thickness multiplied by 100 .

Regional LV function was assessed from LV cycle efficiency which was calculated from LV pressure-wall thickness loops (Fig. 5). The loop area of the pressurewall thickness relationship was determined by planimetry and was divided by the area of the rectangle that encloses the loop ${ }^{(16)}$. Multiple pressure wall thickness loops were recorded on a memory recorder Hioki 8801 (Fig. 5). 


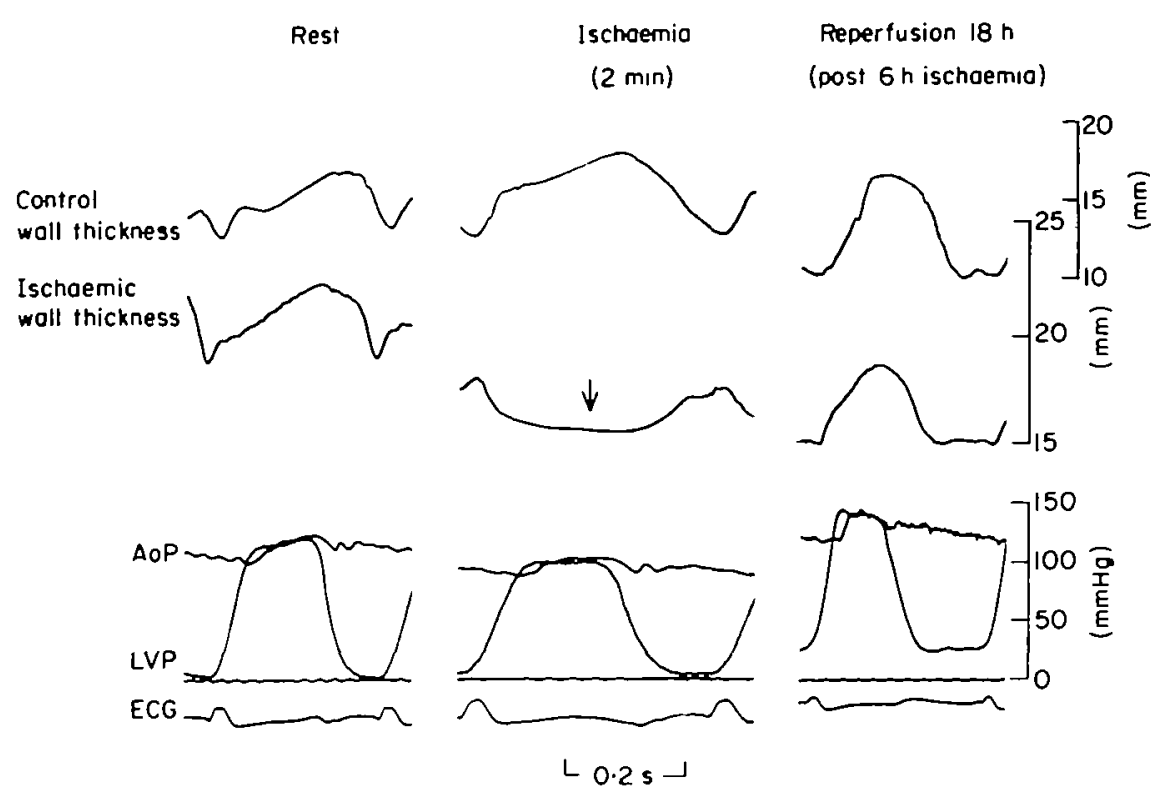

Figure 4 An original tracing showing the haemodynamic variables measured at rest (left), after $2 \mathrm{~min}$ of ischaemia (middle) and after $18 \mathrm{~h}$ of reperfusion (right). Control and ischaemic wall thickness, as well as left vent ncular (LVP) and aortic pressure (AoP) were measured in all anımals. Systolic bulging of the ischaemic wall can be seen during acute ischaemia (arrow), but $18 \mathrm{~h}$ after reperfusion, ischaemic wall thickenıng has reverted to control levels. However, left ventricular function is not completely normal after prolonged ischaemia: there is an increase in the left ventricular end-diastolic pressure (Frank-Starling mechanism) probably due to the ischaemic injury.

\section{Statistics}

Statistical comparisons of data obtained during the control run, after $2 \mathrm{~min}$ and $6 \mathrm{~h}$ of ischaemia, as well as after $18 \mathrm{~h}$ of reperfusion, were performed by an analysis of variance for repeated measurements. Data at rest and at the end of the experiment were compared by a paired $t$-test in the five surviving animals. Data are reported as mean values \pm 1 standard deviation.

\section{Results}

The original tracing illustrating the variables measured are shown in Fig. 4. There is systolic bulging of the ischaemic wall $2 \mathrm{~min}$ after coronary ligation, reversible $18 \mathrm{~h}$ after reperfusion. At the end of the experiment, LV enddiastolic pressure is increased and end-diastolic wall thickness decreased due to pronounced ventricular dilation.

All animals developed ventricular fibrillation after a mean interval of $4 \mathrm{~h}$. Six animals could be defibrillated successfully after a mean time interval of $5 \mathrm{~h}$. Despite several attempts, sinus rhythm could not be restored in two animals and one animal could not be weaned from the assist device at the end of the experiment.

\section{STANDARD HAEMODYNAMICS (TABLE I AND 2)}

Heart rate as well as LV end-diastolic pressure remained constant during the experiment, but both increased significantly at the end of the study under inotropic stimulation with dopamine. Peak systolic pressure decreased significantly during ischaemia and was returned to control levels after $24 \mathrm{~h}$. Maximum $\mathrm{dP} / \mathrm{dt}$ remained unchanged, but increased significantly under the administration of dopamine. The time constant of LV relaxation $(T)$ also increased slightly but significantly after $24 \mathrm{~h}$ experimentation. The pressure asymptote $P_{b}$ decreased parallel to the increase in $\mathrm{T}$.

End-diastolic wall thickness of the control and ischaemic walls remained unchanged during the entire experiment. There was, however, compensatory hyperkinesia of the control wall region during acute ischaemia, whereas the ischaemic wall showed systolic bulging. Eighteen hours after reperfusion and after administration of intravenous dopamine, ischaemic wall thickening was not only normalized, but was even increased when compared to resting wall thickening (ns). Cycle efficiency became negative during ischaemia due to systolic bulging of the ischaemic wall region, but cycle efficiency of both the control $(P<0.05$ vs rest) and the ischaemic wall (ns vs rest) increased after reperfusion and dopamine administration.

\section{LABORATORY MEASUREMENTS (TABLE 3)}

$\mathrm{pH}$ decreased slightly during ischaemia but was returned to control levels after reperfusion. Aortic and pulmonary oxygen saturation decreased during ischaemia and were close to control at the end of the experiment. Serum potassium remained unchanged throughout the experiment, whereas haematocrit continuously decreased. 


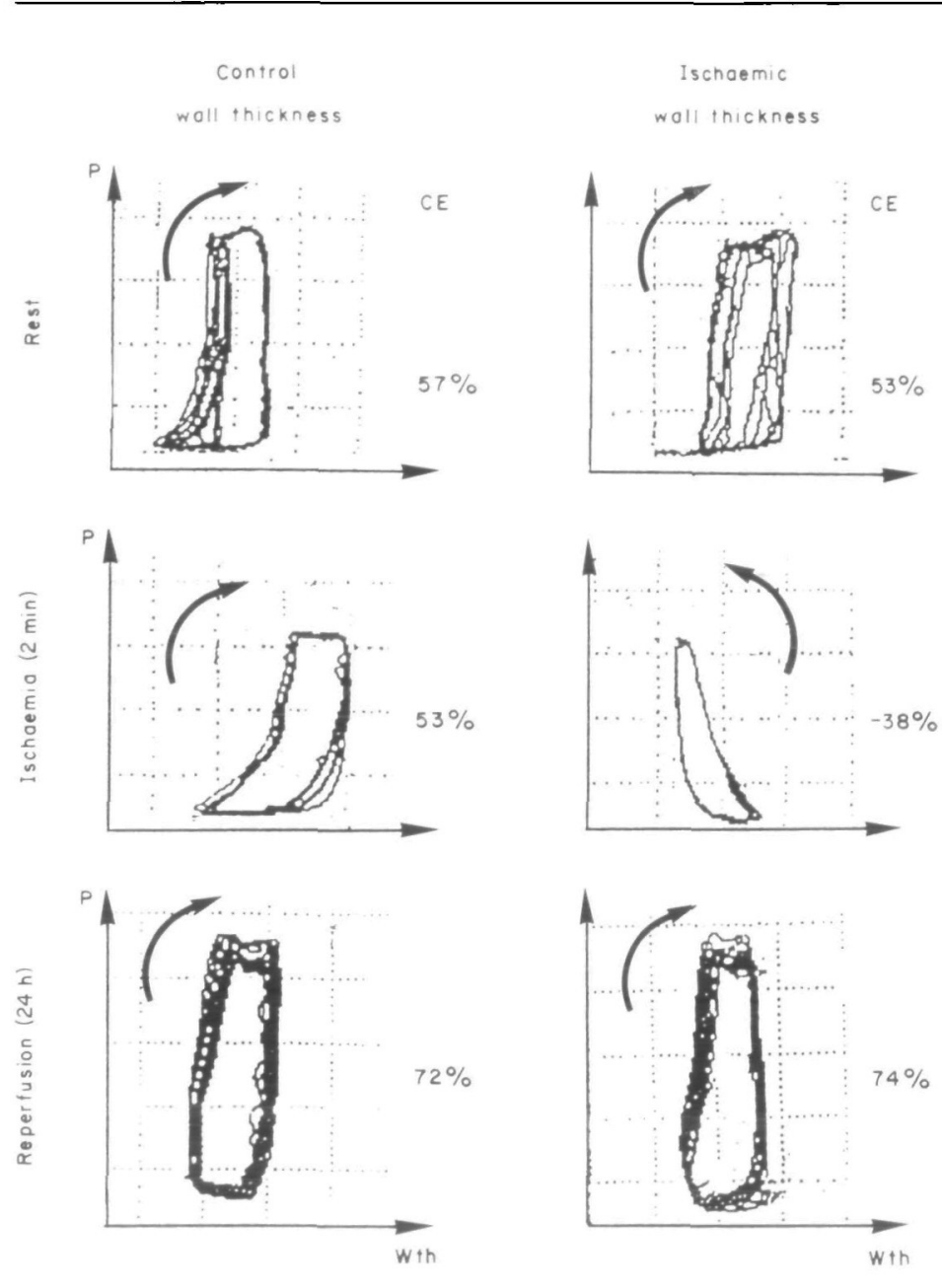

Figure 5 Representative pressure (P)-wall thickness (Wth) loops of the control (left hand panels) and ischaemic wall region (right hand panels). Cycle efficiency (CE) is defined as the ratio of the loop area and the area of the rectangle which encloses the loop. Under control conditions, the pressure-wall thickness loop turns clockwise in both regions, but turns counterclockwise in the presence of systolic bulging after induction of myocardial ischaemia. At the end of the experiment ( $6 \mathrm{~h}$ of ischaemia and $18 \mathrm{~h}$ of reperfusion) both regions show normal clock wise rotations of the pressure-wall thickness loops. For each experimental state, several cardiac cycles are averaged to reduce sampling error.

Table 1 Haemodynamics. Measurements were carried out at rest, after 2 min and after $6 \mathrm{~h}$ of ischaemia as well as at the end of the experiment ( $6 \mathrm{~h}$ of ischaemia $+18 \mathrm{~h}$ of reperfusion $=$ reperfusion)

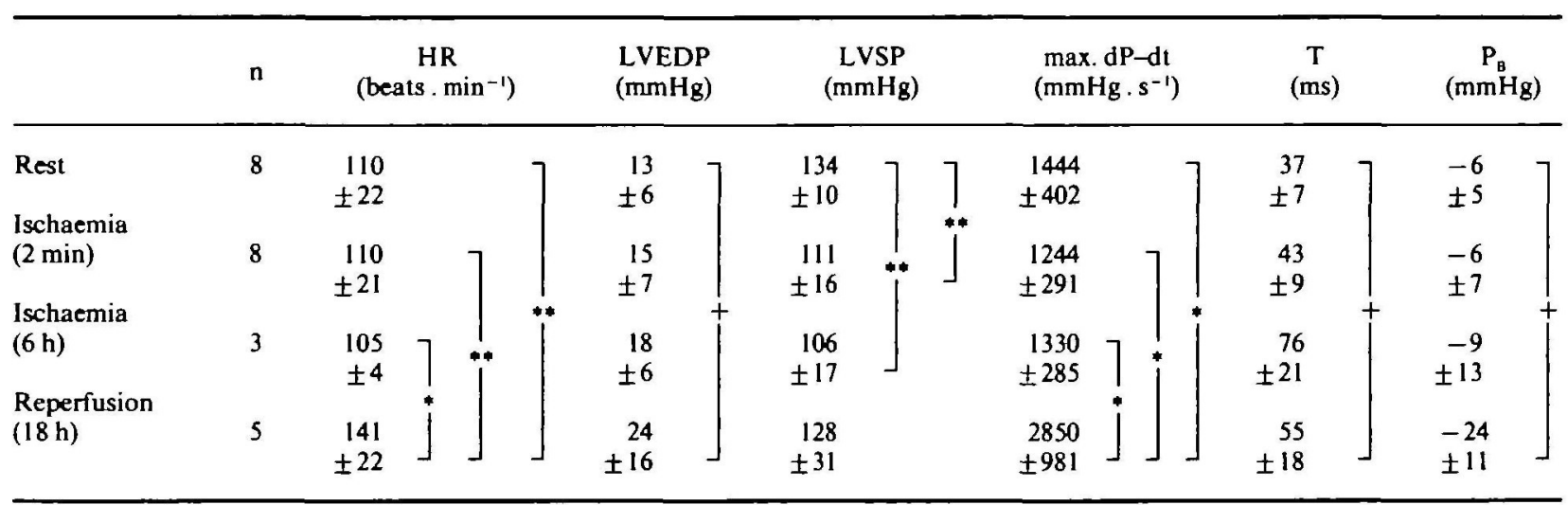

$H R=$ heart rate; $L V E D P=L V$ end-diastolic pressure; $L V S P=L V$ systolic pressure; $\max . \mathrm{dP} / \mathrm{dt}=$ peak positive $\mathrm{dP} ; \mathrm{dt} ; \mathrm{T}=\mathrm{time}$ constant of LV pressure decay; $\mathrm{P}_{\mathrm{a}}=$ pressure asymptote at $\mathrm{dP} / \mathrm{dt}=0 ;{ }^{*} P<0.05 ;{ }^{* *} P<0.01$ (Anova); $+P<0.05$ (paired $\mathrm{t}$-test with $\mathrm{n}=5$ ). 
Table 2 LV wall thickness and cycle efficiency

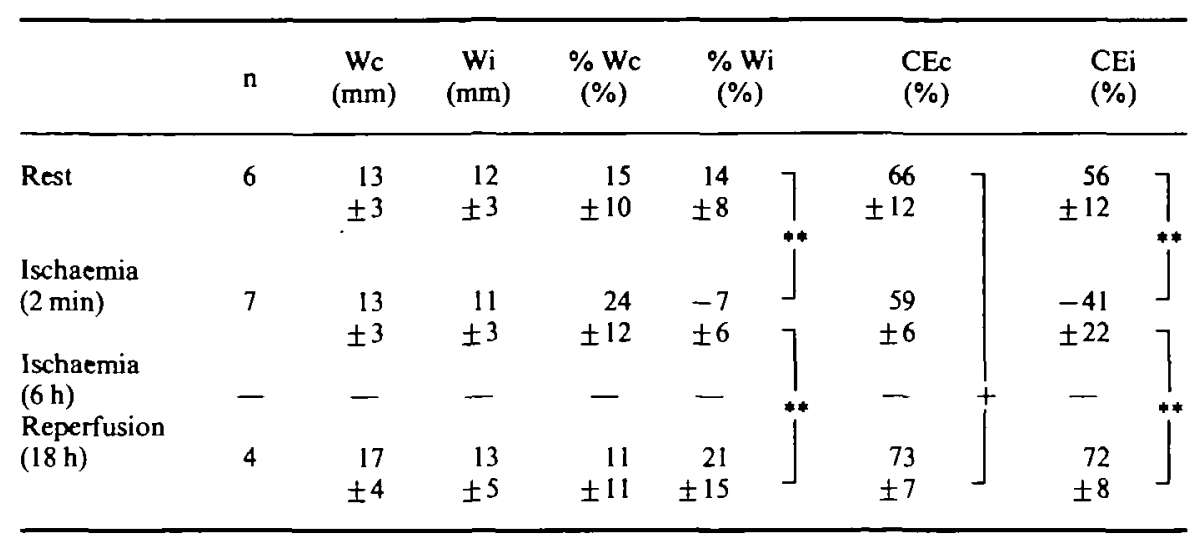

$\mathrm{Wc}=$ control wall thickness; $\mathrm{Wi}=$ ischaemic wall thickness; $\% \mathrm{WC}$ and $\% \mathrm{Wi}=$ sytolic wall thickening of the control and the ischaemic wall; $\mathrm{CEc}=$ cycle efficiency of the control wall region and $\mathrm{CEi}=$ cycle efficiency of the ischaemic wall region (\%); ${ }^{*} P<0.01$ (ANOVA); $+P<0.05$ (paired t-test with $n=4)$. Other abbreviations are as in Table 1 .

Table 3 Laboratory measurements were carried out at rest, after 1 and 6 h of ischaemia as well as at the end of the experiment

\begin{tabular}{|c|c|c|c|c|c|c|}
\hline & $\mathbf{n}$ & $\mathrm{pH}$ & $\begin{array}{c}\text { Ao } \mathrm{O}_{2} \\
(\%)\end{array}$ & $\begin{array}{c}\mathrm{APO} \mathrm{O}_{2} \\
(\%)\end{array}$ & $\begin{array}{c}\mathbf{K}^{+} \\
\left(\mathrm{mmol}^{-1^{-1}}\right)\end{array}$ & $\begin{array}{l}\text { Htk } \\
(\%)\end{array}$ \\
\hline Rest & 8 & $\begin{array}{r}7.48 \\
\pm 0.61\end{array}$ & $\begin{array}{r}96 \\
\pm 5\end{array}$ & $\begin{array}{r}61 \\
\pm 13\end{array}$ & $\begin{array}{r}4.6 \\
\pm 1.1\end{array}$ & $\begin{array}{r}35 \\
\pm 8\end{array}$ \\
\hline $\begin{array}{l}\text { Ischaemia } \\
\text { (1 h) }\end{array}$ & 8 & $\begin{array}{r}7.36 \\
\pm 0.25\end{array}$ & $\begin{array}{r}89 \\
\pm 24\end{array}$ & $\begin{array}{r}39 \\
\pm 15\end{array}$ & $\begin{array}{r}4.9 \\
\pm 0.6\end{array}$ & $\begin{array}{r}30 \\
\pm 10\end{array}$ \\
\hline $\begin{array}{l}\text { Ischaemia } \\
(6 \mathrm{~h}) \\
\text { Reperfusion } \\
(18 \mathrm{~h})\end{array}$ & 8 & $\begin{array}{r}7.36 \\
\pm 0.13 \\
7.46 \\
\pm 0.15\end{array}$ & $\begin{array}{r}93 \\
\pm 8 \\
94 \\
\pm 11\end{array}$ & $\begin{array}{r}47 \\
\pm 16 \\
44 \\
\pm 15\end{array}$ & $\begin{array}{r}4.2 \\
\pm 0.8 \\
4.7 \\
\pm 0.9\end{array}$ & $\begin{array}{r}27 \\
\pm 8 \\
28 \\
\pm 7\end{array}$ \\
\hline
\end{tabular}

Ao $\mathrm{O}_{2}=$ aortic oxygen saturation; AP $\mathrm{O}_{2}=$ pulmonary artery oxygen saturation; $\mathrm{K}^{+}=$serum potassium concentration; Htk = blood haematocrit; ${ }^{*} P<0.05$ (vs rest, paired t-test); ${ }^{* *} P<0.01$ (vs rest, paired t-test).

Table 4 Laboratory findings in five surviving and three non-surviving animals at rest, after 2 min and $6 \mathrm{~h}$ of ischaemia, respectively

\begin{tabular}{|c|c|c|c|c|c|}
\hline & & $\begin{array}{c}C K \\
\left(U .1^{-1}\right)\end{array}$ & $\mathrm{pH}$ & $\begin{array}{r}\mathrm{CO} \\
\text { (1. } \mathrm{min}\end{array}$ & ) \\
\hline $\begin{array}{l}\text { Surviving animals } \\
(n=5)\end{array}$ & $\begin{array}{c}\text { Rest } \\
\text { Ischaemia } \\
(2 \mathrm{~min}) \\
\text { Ischaemia } \\
(6 \mathrm{~h})\end{array}$ & ] & $\begin{array}{l}7 \cdot 48 \\
7.42\end{array}$ & $\begin{array}{l}5 \cdot 1 \\
4 \cdot 5\end{array}$ & \\
\hline $\begin{array}{l}\text { Non-surviving animals } \\
(n=3)\end{array}$ & $\begin{array}{c}\text { Rest } \\
\text { Ischaemia } \\
(2 \mathrm{~min}) \\
\text { Ischaemia } \\
(6 \mathrm{~h})\end{array}$ & $\begin{array}{r}310 \\
5727\end{array}$ & $\begin{array}{l}7 \cdot 48 \\
7.26\end{array}$ & $\begin{array}{l}5.1 \\
3.5\end{array}$ & j \\
\hline
\end{tabular}

$\mathrm{CK}=$ creatinine kinase; $\mathrm{CO}=$ cardiac output measured by thermodilution techniques; ${ }^{*} P<0.05$ (paired t-test), $+P<0.05$ (unpaired t-test). 
COMPARISON OF SURVIVING AND NON-SURVIVING ANIMALS (TABLE 4)

In the non-surviving animals, the increase in creatinine kinase was larger and the drop in $\mathrm{pH}$ greater than in the surviving animals. Cardiac output decreased significantly during ischaemia in both non-surviving and surviving animals, but cardiac output was significantly lower during the 2 min of ischaemia in the non-surviving than surviving animals.

\section{Discussion}

Low cardiac output can be a major complication during acute myocardial ischaemia. Low perfusion pressure with high coronary vascular resistance (increase in filling pressure) can be deleterious for the maintenance of pump function and might aggravate myocardial ischaemia. Immediate unloading of the ventricle prevents cardiogenic shock, reduces myocardial necrosis and maintains adequate perfusion pressure. Several reports ${ }^{[1-5]}$ have shown the benefit of acute unloading in the canine model. The purpose of the present study was to evaluate a new ventricular assist device (BVS 5000 Abiomed) and to examine the effect of immediate mechanical circulatory support on post-ischaemic LV function.

\section{ISCHAEMIA AND UNLOADING}

Proximal ligation of the circumflex coronary artery in the bovine left ventricle is associated with severe myocardial ischaemia, systolic pump failure and electrical instability with ventricular fibrillation. Immediate unloading of both ventricles allows cardiac output to be maintained in the presence of severe ventricular dysfunction (ventricular fibrillation). Severe arrhythmias occurred in all animals after a mean ischaemia time of $4 \mathrm{~h}$. Despite repeated defibrillation, ventricular fibrillation persisted in all but three animals at the end of the $6 \mathrm{~h}$ of ischaemia. In two animals, sinus rhythm could be restored in the reperfusion period, but in the remaining animals ventricular fibrillation persisted $(n=2)$ and one animal could not be weaned from the assist device despite successful defibrillation. The extent of ischaemia was probably larger in the animals who could not be resuscitated because the increase in creatine kinase was larger and the drop in $\mathrm{pH}$ and cardiac output more pronounced in the non-surviving than surviving calves (Table 4).

Thus, mechanical circulatory support helps to maintain cardiac output in the acute phase of myocardial ischaemia with severe arrhythmias. Despite adequate circulatory support with normal blood gases and serum electrolytes, electrical instability could not be avoided. The five animals in which systolic function could be restored had an almost normal LV function at the end of the experiment. However, low cardiac output occurred in these animals and positive inotropic stimulation with intravenous infusion of dopamine had to be given to achieve normal systolic pressure. Since the myocardium could be stimulated with positive inotropic agents, it can be assumed that prolonged myocardial ischaemia was not associated with irreversible myocardial damage ${ }^{[17]}$.
The significant increase in maximum $\mathrm{dP} / \mathrm{dt}$, systolic wall thickening and cycle efficiency after $24 \mathrm{~h}$ compared to the control situation at the beginning of the experiment can be explained by the administration of dopamine. However, normal systolic function could be achieved only with an increase in LV end-diastolic pressure (= Frank-Starling mechanism) (Fig. 4 and Table 1). Apparently, the ischaemic injury was small due to the immediate unloading of the heart which was performed not only during the ischaemic period but also during reperfusion. Therefore, the ventricular assist device not only provides adequate treatment in the acute phase of ischaemia with severe arrhythmias, but also limits the extent of ischaemia and may prevent myocardial necrosis when circulatory support is started early and is extended well into the reperfusion period. Whether a reperfusion period of 6 or $12 \mathrm{~h}$ would have been sufficient to minimize myocardial damage cannot be derived from these data, and no biopsies were taken to prove or exclude myocardial necrosis. However, histological changes are usually minimal $18 \mathrm{~h}$ after an ischaemic event ${ }^{[18]}$.

The occurrence of arrhythmias apparently cannot be prevented by mechanical unloading of the left ventricle. However, arrhythmias are directly related to the extent of myocardial ischaemia and in those animals with large infarcts, resuscitation was not successful. Thus, unloading does not prevent the occurrence of arrhythmias, but allows the heart to recover mechanically after prolonged ischaemia when the ischaemic injury was not too severe. It has to be assumed that the beneficial effect of mechanical unloading is probably permanent in the animals which could be successfully weaned from the ventricular assist device.

\section{REGIONAL AND GLOBAL LV FUNCTION}

Regional LV function was assessed by ultrasonic crystals in a normal and ischaemic region of the left ventricle ( ${ }^{[9]}$; Fig. 3). LV wall thickening of the ischaemic region showed systolic bulging during coronary occlusion and, as a consequence, cycle efficiency became negative (16]; Fig. 5). Passive elongation of the ischaemic region and systolic contraction of the control region caused LV asynergy ${ }^{[1]}$ with a reduction in global mechanical efficiency. The loss of contractile work performed by the ischaemic zone was partially compensated by regional hyperkinesia of the control wall region (Table 2). Despite these regional abnormalities in wall thickening, global function parameters such as maximum $\mathrm{dP} / \mathrm{dt}$ and the time constant of isovolumic relaxation (T) remained almost unchanged during acute myocardial ischaemia. However, under inotropic stimulation both maximum $\mathrm{dP} / \mathrm{dt}$ and the time constant $T$ were significantly increased, suggesting enhanced contractility (maximum $\mathrm{dP} / \mathrm{dt}$ ) but at the same time delayed relaxation ( $T$ ). An increase in inotropic state augments the speed of relaxation in the normal heart and thus decreases the time constant $T^{[20]}$. In the present analysis, however, $T$ increased despite administration of dopamine. This can be interpreted as a sign of diastolic dysfunction in the presence of maintained systolic function. 


\section{LIMITATIONS OF THE STUDY}

Collateral blood flow was not estimated in the present study due to technical reasons. It is, however, possible that collateral circulation played an important role in limiting myocardial damage after coronary ligation. It has to be realized that systolic bulging would not have occurred if significant collateral circulation had been present (Fig. 3). Thus, it has to be assumed that collatera! circulation was not an important factor in preserving ventricular function in the present study. Furthermore, without mechanical circulatory support there would have been no survivors after several hours of ventricular fibrillation. Since ventricular fibrillation occurred in all animals, other unloading interventions, such as counterpulsation or vasodilation, could not have been successful because biventricular assistance is necessary to maintain cardiac output over prolonged ventricular fibrillation.

\section{References}

[1] Anstadt MP, Malone JP, Brown JR, Nolan DS, Quinones JD, Anstadt GL. Direct mechanical ventricular assistance promotes salvage of ischemic myocardıum. Trans Am Soc Artif Intern Organs 1987; 33. 720-5.

[2] Wel C, Yada I, Kusagawa M. The effect of left ventricular assistance on the area of infarcted myocardium. Trans Am Soc Artif Intern Organs 1986; 32: 217-20.

[3] Skınner DB, Anstadt GL, Camp ThF. Acute circulatory support by mechanical ventricular assistance following myocardial infarction. J Thorac Cardiovasc Surg 1967; 54: 785-94.

[4] Magovern GJ, Christlieb IY, Kao RL et al. Recovery of the falling canine heart with biventricular support in a previously fatal experimental model. J Thorac Cardiovasc Surg 1987; $94^{\circ}$ 656-63.

[5] LeGal YM, Rideout SC. Reduction of myocardial infarct size: A comparison of the effectiveness of intra-aortic ballon pumping and transapical left ventricular bypass. Trans Am Soc Artif Intern Organs 1983; 29: 593-8.

[6] Farrar DJ, Hill JD, Gray LA et al. Heterotopic prosthetic ventricles as a bridge to cardiac transplantation: A multicenter study in 29 patients. N Engl J Med 1988; 318: 333-40.
[7] Bregman D, Drusin R, Lamb J, Reemtsma K, Rose E. Hear transplantation in patients requiring mechanical circulatory support. Heart Transplant 1982; 1: 154-7.

[8] Hill JD, Farrar DJ, Hershon JJ. Use of prosthetic ventricle as a bridge to cardiac transplantation for postinfarction cardiogenic shock. N Engl J Med 1986; 314: 627-8.

[9] Ninet J, Jarolin G, Vigneron $M$ et al. Technique d'implantation des procédés d'assitance biventriculaire externe. Pres Med 1989; 18: $1024-7$.

[10] Wooley SR, Wesenhagen $H$, Jambroes $G$, Hitchcock JF. Experience with the abiomed biventricular support system. Eur Heart J 1989; 10: 91 (abstr).

[11] Hess OM, Osakada G, Lavelle JF, Gallagher KP, Kemper WS, Ross J Jr. Diastolıc myocardial wall stiffness and relaxation during partial and complete coronary occlusions in the conscious dog. Circ Res 1983; 52: 387-400.

[12] Rankin JS, McHale PA, Arentzen CE, Ling D, Greenfield JC, Anderson RW. The three-dimensional dynamic geometry of the left ventricle in the conscious dog. Circ Res 1976; 39: 304-13.

[13] Von Segesser LK, Leskosek B, Rheda F el al. Performance characteristics of a disposable ventricle assist device. Thorac Cardiovase Surg 1988; 36: 146-50.

[14] Carroll JD, Hess OM, Hirzel HO, Krayenbuehl HP. Exerciseinduced ischemia: the influence of altered relaxation on early diastolic pressures. Circulation 1983; 67: 521-8.

[15] T,on-A-Meeuw L, Hess OM, Nonogi H, Monrad ES, Leskosek B, Krayenbuehl HP. Left ventricular volume determination in dogs: a comparison between conductance technique and angiocardiography. Eur Heart J 1988; 9: 1018-26.

[16] Gibson DG, Brown DJ. Assessment of left ventricular systolic function in man from simultaneous echocardiographic and pressure measurements. Br Heart J 1976; 38: 8-17.

[17] Braunwald E, Kloner RA. The stunned myocardium: prolonged, postischemic ventncular dysfunction. Circulation 1982; 66: $1146-9$.

[18] Schneider J. Kapitel Herz. In: Laissue JA, Gebber JO, eds Einführung in die spezielle Pathologie. Stuttgart, New York: Gustav Fischer Verlag, 1991: 146.

[19] Oskada G, Hess OM, Gallagher KP, Kemper WS, Ross J Jr End-systolic dimension-wall thickness relations during myocardial ischemia in conscious dogs. A new approach for defining regional function. Am J Cardiol 1983; 51: 1750-8.

[20] Carroll JD, Hess OM, Hirzel HO, Turina M, Krayenbuehl HP Left ventricular systolic and diastolic function in coronary artery disease: effects of revascularisation on exercise-induced ischemia. Circulation 1985, 72: 119-29 